\title{
A metabolomic approach to characterize the acid-tolerance response in Sinorhizobium meliloti
}

\author{
Walter Omar Draghi ${ }^{1}$ María Florencia Del Papa ${ }^{1}$ Aiko Barsch ${ }^{2}$. \\ Francisco J. Albicoro $^{1}$ - Mauricio J. Lozano ${ }^{1}$ - Alfred Pühler ${ }^{2} \cdot$ Karsten Niehaus $^{2}$. \\ Antonio Lagares ${ }^{1}$
}

Received: 3 February 2017 / Accepted: 17 April 2017

(C) Springer Science+Business Media New York 2017

\begin{abstract}
Introduction Sinorhizobium meliloti establishes a symbiosis with Medicago species where the bacterium fixes atmospheric nitrogen for plant nutrition. To achieve a successful symbiosis, however, both partners need to withstand biotic and abiotic stresses within the soil, especially that of excess acid, to which the Medicago-Sinorhizobium symbiotic system is widely recognized as being highly sensitive.

Objective To cope with low $\mathrm{pH}, S$. meliloti can undergo an acid-tolerance response $(\operatorname{ATR}(+))$ that not only enables a better survival but also constitutes a more competitive phenotype for Medicago sativa nodulation under acid and neutral conditions. To characterize this phenotype, we employed metabolomics to investigate the biochemical changes operating in $\operatorname{ATR}(+)$ cells.

Methods A gas chromatography/mass spectrometry approach was used on S. meliloti 2011 cultures showing $\operatorname{ATR}(+)$ and ATR(-) phenotypes. After an univariate and multivariate statistical analysis, enzymatic activities and/or reserve carbohydrates characterizing ATR(+) phenotypes were determined.
\end{abstract}

Electronic supplementary material The online version of this article (doi:10.1007/s11306-017-1210-2) contains supplementary material, which is available to authorized users.

Walter Omar Draghi

wdraghi@biol.unlp.edu.ar

1 IBBM - Instituto de Biotecnología y Biología Molecular, CCT La Plata, CONICET - Departamento de Ciencias Biológicas, Facultad de Ciencias Exactas, Universidad Nacional de La Plata, Calles 47 y 115, 1900 La Plata, Argentina

2 CeBiTec - Centrum für Biotechnologie, Universität Bielefeld, Bielefeld, Germany
Results Two distinctive populations were clearly defined in cultures grown in acid and neutral $\mathrm{pH}$ based on the metabolites present. A shift occurred in the carbon-catabolic pathways, potentially supplying $\mathrm{NAD}(\mathrm{P}) \mathrm{H}$ equivalents for use in other metabolic reactions and/or for maintaining intracellular-pH homeostasis. Furthermore, among the mechanisms related to acid resistance, the ATR $(+)$ phenotype was also characterized by lactate production, envelope modification, and carbon-overflow metabolism.

Conclusions Acid-challenged S. meliloti exhibited several changes in different metabolic pathways that, in specific instances, could be identified and related to responses observed in other bacteria under various abiotic stresses. Some of the observed changes included modifications in the pentose-phosphate pathway (PPP), the exopolysaccharide biosynthesis, and in the myo-inositol degradation intermediates. Such modifications are part of a metabolic adaptation in the rhizobia that, as previously reported, is associated to improved phenotypes of acid tolerance and nodulation competitiveness.

Keywords Metabolomics - Sinorhizobium meliloti . Acid-tolerance response $\cdot$ Acid stress

\section{Introduction}

Sinorhizobium meliloti is an $\alpha$-proteobacterium able to establish a nitrogen-fixing symbiosis in indeterminate root nodules with legumes of the genera Medicago, Melilotus, and Trigonella. The capacity to fix atmospheric nitrogen for plant nutrition gives these associations a fundamental relevance to the nitrogen cycle, thus making rhizobia a subject of interest in agricultural-production systems as well. 
Environmental conditions play an essential role in the control of legume-Rhizobium interactions. The establishment of a successful symbiotic interaction is coordinated by both partners and involves a complex system of intercommunication (Gage 2004; Gibson et al. 2008; Jones et al. 2007). This interaction will be successful if the symbiotic partners are able to overcome different biotic and abiotic conditions of the environment that, upon being present could interfere with bacterial persistence, infection, nodulation, and nitrogen-fixation activity. High soil temperature, salinity, and moisture; metal toxicity; nutrient deficiency; and acid or alkaline $\mathrm{pH}$ are some of the environmental features that impose stress on both symbiotic partners (Zahran 1999).

The Sinorhizobium-Medicago symbiosis has been known for years to be extremely sensitive to acid stress (O'Hara et al. 1989; Glenn et al. 1999; Glenn and Dilworth 1994). A low pH in soil affects plant development, bacterial viability, and also several steps in bacteriumplant recognition and nodule formation (Glenn et al. 1999; Kochian et al. 2004; Caetano-Anollés et al. 1989; Ferguson et al. 2013). Accordingly, diverse approaches have been used to characterize the biological mechanisms that govern the resistance to acid stress of $S$. meliloti, as a model bacterium, and that could be targets for the biotechnologic manipulation of inoculants in order to improve their symbiosis performance in acid environments (Dilworth et al. 2001). Several mutagenesis studies have been carried out in Sinorhizobium strains to discover the genes involved in acid tolerance. These approaches have detected several loci whose expression varies according to the ambient pH (Reeve et al. 1998; Riccillo et al. 2000; Tiwari et al. 1996a, b; Vinuesa et al. 2003). None of these genes alone, however, is able to generate a phenotype completely tolerant or sensitive to acidity, thus pointing to the multigenic nature of the bacterial response to acid stress. On the basis of these observations, several omics approaches have been used to characterize the biological systems acting on acid-stressed cells (Reeve et al. 2004; Tiwari et al. 2004; Hellweg et al. 2009). Our laboratory recently contributed to an elucidation of the molecular mechanisms underlying the regulation of the crucial physiologic changes that occur in acid-stressed bacteria. In particular, Draghi et al. (2016) reported an integrated analysis entailing a combination of transcriptomic, metabolomic, and proteomic analyses of the responses of $S$. meliloti under controlled growth rates and $\mathrm{pH}$ in chemostat culture. The observed response to acidic $\mathrm{pH}$ was not based on a few specific genes, but rather involved whole sets of RNAs, proteins, and metabolites associated with various cellular functions. Under the low-pH conditions imposed in the chemostat, we demonstrated that the pentose-phosphate pathway (PPP) in those cultures exhibited increases in various transcripts, enzymes, and metabolites compared to $S$. meliloti cells grown at neutral pH (Draghi et al. 2016).

In addition, as with other bacteria, $S$. meliloti manifested an acid-tolerance response $(\operatorname{ATR}(+))$ when faced with otherwise lethal acidic conditions (Dilworth et al. 1999; O'Hara and Glenn 1994). This class of responsedefined as a cellular resistance to acid shock after growth for a determined length of time at a moderately low $\mathrm{pH}-$ exemplifies the variation in the phenotype of the cells relative to that under the previous growth conditions. That $S$. meliloti from acid-adapted cultures (of phenotype ATR $(+)$ ) exhibited an improved competitiveness for nodulation of the host plant Medicago sativa under growth conditions involving both acid and neutral $\mathrm{pH}$ is furthermore highly relevant (Draghi et al. 2010). In this regard, the $\operatorname{ATR}(+)$ phenotype not only becomes essential when bacteria must withstand acid stress, but also represents a desirable trait for rhizobial selection in acid environments in order to achieve a successful symbiosis under otherwise nonoptimal circumstances.

The availability of $S$. meliloti ATR(+) strains enabled the possibility to biotechnologically manipulate the bacterial culture conditions of strains that possessed recognized nitrogen-fixation abilities but exhibited poor performance in acidic soils. In order to obtain rhizobial inoculants with improved biological capabilities in such environments, further work will be required to increase our knowledge concerning both the molecular details responsible for acid tolerance and the characteristics of the rhizobial physiology during the processes leading to the acid-tolerant state. Within this context, one essential aspect that has not yet been studied is the metabolic alteration that occurs in rhizobia during the adaptive response to sublethal acidity- $\mathrm{i}$. e., the $\operatorname{ATR}(+)$ phenotype. In the present work, this point was investigated through the application of a metabolomic approach to characterize the $S$. meliloti 2011.The experimental approach presented here served to highlight the metabolic changes associated to the process of transient acid adaptation in a model rhizobia.

\section{Materials and methods}

\subsection{Bacterial strains and culture conditions}

Sinorhizobium meliloti 2011 batch cultures were established in Evans minimal medium (Evans et al. 1970) containing $10 \mathrm{~g} \mathrm{~L}^{-1}$ glucose as carbon source and $0.7 \mathrm{~g} \mathrm{~L}^{-1}$ ammonium chloride as nitrogen source. The $\mathrm{pH}$ was controlled by the addition of $20 \mathrm{mM} 2-(N$-morpholino $)$ ethanesulfonic acid or $20 \mathrm{mM}$ 1,4-piperazine-diethanesulfonic acid piperazine to keep the $\mathrm{pH}$ close to 6.1 or 
7.0, respectively. The rhizobia were grown at $28^{\circ} \mathrm{C}$ and 250 r.p.m. in a rotary shaker up to the early $\log$ phase of growth $\left(\mathrm{OD}_{600}, 0.2 \pm 0.05\right)$. Each primary culture was inoculated at a density insuring at least two generations of growth before harvesting.

\subsection{Metabolomic profiling}

From $200 \mathrm{ml}$ of early log-phase cultures, cells were harvested by entrapment upon filtration through a $0.45-\mu \mathrm{m}$ nitrocellulose filter membrane. The retained bacteria were scraped off the membrane and directly frozen in liquid nitrogen before lyophilization. The procedures for sample derivatization and metabolite identification and quantification by gas-chromatography-mass-spectrometry (GC-MS) were performed without modifications as described by Barsch et al. (2004). The relative peak area of each compound was determined by normalization to the ribitol internal standard $(10 \mu \mathrm{M})$. Six replicates (10-30 mg cells dry weight) under each $\mathrm{pH}$ condition were analyzed.

\subsection{Determination of enzymatic activities}

Early log-phase cells from $100 \mathrm{ml}$ cultures were centrifuged at $10,000 \times g$ for $30 \mathrm{~min}$ at $4{ }^{\circ} \mathrm{C}$ and washed once with phosphate buffer saline and the resulting pellets lyophilized for storage at $-20^{\circ} \mathrm{C}$ until use. The dry cells were resuspended in $2 \mathrm{ml}$ of Tris- $\mathrm{HCl} 0.08 \mathrm{M}, \mathrm{pH} 7.5$ and sonicated three times for $30 \mathrm{~s}$ at $50 \%$ power (Vibracell, Sonics \& Materials Inc, Newtown, CT, USA). After cell disruption, the suspension was centrifuged at $30,000 \times g$ for $30 \mathrm{~min}$ at $4^{\circ} \mathrm{C}$ to precipitate cell debris. The total protein content was measured in the supernatant with a Bradford Protein Assay Kit (Bio-Rad Lab, Hercules, CA, USA).

Lactate deydrogenase activity was measured by the phenazine-methosulfate- (PMS-) coupled reduction of 3-(4,5-dimethylthiazol-2-yl)-2,5-diphenyl-2H-tetrazolium bromide (MMT) as described by Futai (1973). One ml of reaction mixture contained $0.08 \mathrm{M}$ Tris $\mathrm{HCl} \mathrm{pH} \mathrm{7.5,} 120 \mu \mathrm{g}$ PMS, $60 \mu \mathrm{g}$ MTT, $2 \mathrm{mM}$ D,L-lactic acid, and $10 \mathrm{mM}$ NAD. The absorbance was measured at $570 \mathrm{~nm}$ after $30 \mathrm{~min}$ of incubation at $37^{\circ} \mathrm{C}$.

Urease activity was measured by quantitating the rate of ammonia release from urea to form indophenol, the generation of which reaction product was measured at $640 \mathrm{~nm}$ by the phenolhypochlorite method (Solorzano 1969). One unit of urease activity was defined as the amount of enzyme required for the hydrolysis of $1 \mu \mathrm{mol}$ of urea per min at $37^{\circ} \mathrm{C}$. The assay contained $25 \mathrm{mM} \mathrm{N}-2$ hydroxyethylpiperazine- $N$ '-2-ethanesulfonic acid $\mathrm{pH} 7.75$, $0.5 \mathrm{mM}$ ethylenediaminetetraacetic acid, and $50 \mathrm{mM}$ of the urea substrate.
Myo-inositol dehydrogenase activity was assayed by a modified procedure described by Poole et al. (1994) and determined at $570 \mathrm{~nm}$ by the PMS-coupled reduction of MMT, as cited above. The reaction buffer contained $50 \mathrm{mM} \mathrm{NH}{ }_{4} \mathrm{Cl}, 0.4 \mathrm{mM} \mathrm{NAD}+, 50 \mathrm{mM} \mathrm{Na}_{2} \mathrm{CO}_{3} \mathrm{pH} 10$, and $100 \mathrm{mM}$ myo-inositol. One unit of enzyme was defined as the amount of enzyme required to reduce of $1 \mu \mathrm{mol}$ of MTT per min at $24{ }^{\circ} \mathrm{C}$, at an $\varepsilon$ value of $17 \mathrm{mM}^{-1} \mathrm{~cm}^{-1}$ (Kistler and Lin 1971).

The absorbance obtained from enzyme-catalysed reactions was adjusted by subtracting background values from a reaction containing no substrate. All the experiments were performed in triplicate and the differences in activities analysed statistically by the Student $t$ test.

\subsection{Quantification of the content of polyhydroxybutyrate (PHB) and exopolysaccharides (EPSs)}

Sinorhizobium meliloti pellets (10-20 mg of cells dry weight) were homogenized with sodium hypochlorite overnight at room temperature, washed with double-distilled water, precipitated with 1:1 alcohol:acetone, and resuspended in chloroform (Quelas et al. 2013). PHB was then determined as crotonic acid in $\mathrm{H}_{2} \mathrm{SO}_{4}$ (Law and Slepecky 1961). To isolate the EPSs, the supernatant from $200 \mathrm{ml}$ of culture was first lyophilized to reduce the volume tenfold, then the EPSs were precipitated with three volumes of cold ethanol and the suspension incubated at $-20^{\circ} \mathrm{C}$ overnight, and finally the supernatant was centrifuged $10,000 \times g$ for $15 \mathrm{~min}$. The pellet was dissolved in water, dialyzed against distilled water, lyophilized, and stored at $-80^{\circ} \mathrm{C}$ until use. The amount of EPS in these samples was determined by the anthrone method as previously described (Trevelyan et al. 1952).

\subsection{Determination of NADH and NAD+ concentrations}

From 10 to $15 \mathrm{mg}$ of cells dry weight, the NADH and NAD+ pools were extracted in acid or alkaline buffer according to the protocol described by Leonardo et al. (1996). The supernatants obtained were assayed for NADH and NAD+by measuring the continuous spectrophotometric rate. For NADH, the reaction contained $100 \mathrm{mM}$ $\mathrm{Na}_{2} \mathrm{HPO}_{4} \mathrm{pH} 7.5,2.3 \mathrm{mM}$ sodium pyruvate, $0.033 \%(\mathrm{w} / \mathrm{v})$ bovine-serum albumin, and 2-4 units of lactate dehydrogenase (Sigma). NADH standards from 0 to $0.2 \mathrm{mM}$ were used for cofactor quantification. For NAD+, the reaction contained $100 \mathrm{mM} \mathrm{Na} \mathrm{HPO}_{4} \mathrm{pH} 7.5,3 \mathrm{mM}$ sodium lactate, $0.033 \%(\mathrm{w} / \mathrm{v})$ bovine-serum albumin, and 2-4 units of lactate dehydrogenase (Sigma). NAD+standards from 0 to $0.10 \mathrm{mM}$ were used. The reactions were carried out 
at $37^{\circ} \mathrm{C}$ and the increase in absorbance at $340 \mathrm{~nm}$ read at 5 min after enzyme addition.

\subsection{Statistical data analysis}

Data matrix obtained was used for uni- and multivariate analysis. All metabolite concentrations were log-transformed and standardized (mean: 0 and standard deviation: 1) before the statistical analysis. The MetaboAnalyst 2.0 web server was used for data normalization and univariate data analysis ( $t$ test and metabolites Fold change) (Xia et al. 2012). For multivariate analysis, transformed data matrix was exported into SIMCA-P 14.0 (Umetrics, Umeå, Sweden) and the supervised orthogonal partial least square discriminant analysis (OPLS-DA) was applied in order to reveal significant differences between the metabolic fingerprints associated with the $\mathrm{pH}$ treatments. The efficiency and reliability of the PLS-DA models was assessed by R2X, R2Y and Q2 parameters, permutation tests $(n=999)$, and performing a sevenfold internal cross validation-analysis of variance $(\mathrm{CV}-\mathrm{ANOVA}, p$ value $\leq 0.01)$. The discriminating metabolites were selected when Variable Importance in the Projection (VIP) values where higher than 1 (VIP $>1.0$ ).

\section{Results}

\subsection{Metabolite profiling of S. meliloti 2011 growing at different pHs in batch cultures}

In order to obtain a snapshot of the metabolome of ATR(+) rhizobia compared to that of non-adapted cells to low $\mathrm{pH}$, we performed a metabolome analysis on rhizobia from cultures grown at $\mathrm{pH} 6.1$ and 7.0 respectively, which were harvested by rapid filtration and then frozen in liquid nitrogen as previously described by Barsch et al. (2004). The cell metabolites were extracted with methanol and then analysed by GC-MS after derivatization. A total of 61 metabolites, mainly involved in the metabolism of carbon and nitrogen compounds, could be identified and quantified (Supplementary Table 1). The univariate statistical analysis applied to the set of normalized data indicated that 21 metabolites (34.4\%) became significantly varied in their intracellular concentrations (Student $t$ test, $p \leq 0.05$ ) when the extracellular $\mathrm{pH}$ was either $\mathrm{pH} 7.0$ or $\mathrm{pH} 6.1$ (Table 1). The orthogonal partial least squares discriminant multivariate analysis (OPLS-DA) demonstrated that bacteria derived from the neutral and acid cultures could be differentiated on the basis of their corresponding metabolome profiles (Fig. 1). The validation of the OPLS-DA model showed good predictability $(\mathrm{Q} 2=0.818)$ and goodness of fit values $(\mathrm{R} 2 \mathrm{X}=0.542, \mathrm{R} 2 \mathrm{Y}=0.954)$, and the cross validation analysis of variance showed lower values than the threshold $(p=0.00996)$. In addition, permutation plots comparing the goodness of fit (R2 and Q2) of the PLSDA models with the goodness of fit of Y-permutated models (Supplementary Fig. 1) fulfilled the requirements to validate the model, as Q2 values from permutated models are lower than Q2 values from the original model and the regression line of the Q2-points intersects the vertical axis at, or below zero (Graham et al. 2016). Inspection of those components whose variable importance in projection (VIP) values were higher than one in the OPLS-DA revealed that 26 metabolites were informative for a discrimination of cells according to their $\mathrm{pH}$ of growth (Table 1, rightmost column).

\subsection{Metabolic pathways of $S$. meliloti affected by the extracellular pH during growth in batch cultures}

Modification of the $\mathrm{pH}$ of the culture medium from 7.0 to 6.1 resulted in changes in several compounds of central carbon (C) metabolism (Fig. 2). Acidic conditions produced an increase in the concentration of the first intermediates in the glucose-degradation pathways, including glucose6-P, gluconolactone, gluconate, and gluconate-6-P. All these metabolites belong to a set of reactions shared in common between the oxidative branch of the PPP and the Entner-Doudoroff pathway (EDP; Fuhrer et al. 2005). Several three-carbon (triose) compounds derived from glucose catabolism also underwent changes in cytosolic concentration at the more acid extracellular $\mathrm{pH}$. Whereas glycerate3-P, glycerate-2-P, phosphoenolpyruvate (PEP), and lactate all had higher concentrations in acid-grown cells, the concentration of pyruvate was lower at $\mathrm{pH}$ 6.1. No significant changes were observed in the metabolites of the tricarboxylic-acid cycle during batch-culture growth of the bacteria under both $\mathrm{pH}$ conditions.

Several amino acids and/or their intermediates also became significantly varied in concentration upon alteration of the extracellular $\mathrm{pH}$ (Fig. 3). At pH 6.1, serine levels increased, but alanine concentrations were lower. In addition, several intermediate compounds in the biosynthesis of methionine became elevated at acid pH. Likewise, the levels of shikimate - a biosynthetic precursor of aromatic amino acids-were higher at pH 6.1; whereas 2-isopropylmalate - an intermediate in the biosynthesis of branchedchain amino acids - along with urea-an end product in arginine metabolism—-both became decreased at acid $\mathrm{pH}$.

\subsection{Enzyme activities related to some of the observed changes in the metabolome}

\subsubsection{Lactate dehydrogenase}

In view of the variation in the cytosolic concentration of lactate at changes in the extracellular $\mathrm{pH}$ of the batch 
Table 1 Statistical analysis of metabolite concentrations under different $\mathrm{pH}$ conditions

\begin{tabular}{|c|c|c|c|c|c|}
\hline & & $p$ value & Fold change & $\log _{2}\left(\mathrm{FC}^{\mathrm{a}}\right)$ & VIP scores \\
\hline 1 & Gluconate-6-P & $4.30 \times 10^{-10}$ & 26.29 & 4.72 & 1.59 \\
\hline 2 & Glycerate-3-P & $1.46 \times 10^{-5}$ & 6.85 & 2.78 & 1.47 \\
\hline 3 & Gluconate & $9.61 \times 10^{-5}$ & 2.84 & 1.51 & 1.40 \\
\hline 4 & Phosphoenolpyruvate & $1.66 \times 10^{-3}$ & 2.37 & 1.24 & 1.31 \\
\hline 5 & Serine & $2.31 \times 10^{-3}$ & 3.39 & 1.76 & 1.44 \\
\hline 6 & Homoserine & $3.08 \times 10^{-3}$ & 14.37 & 3.85 & 1.41 \\
\hline 7 & Fructose & $4.49 \times 10^{-3}$ & 2.29 & 1.19 & 1.40 \\
\hline 8 & Glycerate & 0.01 & 1.81 & 0.86 & 1.31 \\
\hline 9 & $O$-succinyl-homoserine & 0.01 & 1.80 & 0.85 & 1.36 \\
\hline 10 & Fructose-6-P & 0.01 & 1.44 & 0.53 & 1.24 \\
\hline 11 & Glycerate-2-P & 0.01 & 1.90 & 0.93 & 1.28 \\
\hline 12 & 2-Isopropylmalate & 0.01 & 0.61 & -0.72 & 1.17 \\
\hline 13 & Urea & 0.01 & 5.95 & 2.57 & 1.25 \\
\hline 14 & Pyruvate & 0.01 & 0.63 & -0.66 & 1.14 \\
\hline 15 & Homocysteine & 0.02 & 1.68 & 0.75 & 1.20 \\
\hline 16 & Glucose-6-P & 0.02 & 1.35 & 0.43 & 1.14 \\
\hline 17 & Lactate & 0.02 & 1.91 & 0.93 & 1.04 \\
\hline 18 & Alanine & 0.03 & 0.53 & -0.91 & 1.10 \\
\hline 19 & Sucrose & 0.03 & 1.89 & 0.92 & 1.08 \\
\hline 20 & Gluconolactone & 0.03 & 1.39 & 0.48 & 1.11 \\
\hline 21 & Shikimate & 0.05 & 1.53 & 0.61 & 1.05 \\
\hline$* 22$ & $\alpha$-Glycerophosphate & 0.06 & 1.29 & 0.37 & 1.09 \\
\hline$* 23$ & Methylcitrate & 0.06 & 1.48 & 0.56 & 1.17 \\
\hline$* 24$ & Proline & 0.06 & 2.15 & 1.10 & 1.12 \\
\hline$* 25$ & Uracil & 0.06 & 1.42 & 0.51 & 1.05 \\
\hline$* 26$ & Myoinositol & 0.06 & 1.47 & 0.56 & 1.16 \\
\hline
\end{tabular}

The table shows significantly different metabolites according to the univariate $(p \leq 0.05)$ or the multivariate variable-importance-in-projection (VIP) values. Those metabolites whose VIP values are $\geq 1$ and $p$ values $\geq 0.05$ are marked with asterisks $(*)$

${ }^{\mathrm{a}} \mathrm{FC}$, fold change in concentration at $\mathrm{pH} 6.1$ relative to the value at $\mathrm{pH} 7.0$ cultures, we investigated the total L-lactate dehydrogenase (LDH) activities in rhizobia grown at $\mathrm{pHs} 6.1$ and 7.0 as indicated in Materials and Methods (Fig. 4, Panel a). The $S$. meliloti genome contains four genes encoding for putative lactate dehydrogenases: SMc01455 ( $d l d)$, SMc01712 (lldD2), and SMc01740 (lldD1), all chromosomally located, along with SMb20850 (lldD3) carried by the pSymB megaplasmid (Capela et al. 2001). Rhizobial cells grown at $\mathrm{pH} 6.1$ contained a much higher LDH activity than that observed at $\mathrm{pH}$ 7.0. This result was consistent with the higher concentration of lactate and lower level of pyruvate recorded in the rhizobia grown at $\mathrm{pH} 6.1$ than the corresponding values for those intermediates at $\mathrm{pH}$ 7.0.

\subsubsection{Myo-inositol dehydrogenase}

ATR(+) rhizobia had a higher concentration of myo-inositol than the ATR(-) rhizobia grown at pH 7.0 (Table 1). The catabolism of myo-inositol in $S$. meliloti is mediated by a myo-inositol dehydrogenase encoded by the gene idhA (SMb20899) located in the pSymB megaplasmid. This gene plays a key role in the symbiosis of the rhizobia with Medicago sativa plants (Kohler et al. 2010) and also in the symbiosis of other rhizobia, such as Sinorhizobium freddii USDA191 (Jiang et al. 2001) and Rhizobium leguminosarum bv. viciae (Fry et al. 2001) with their corresponding host plants. Figure 4, Panel b depicts the markedly higher activity of myo-inositol dehydrogenase in the $\mathrm{ATR}(+)$ rhizobia than in the ATR(-) rhizobia, thus pointing to a role of myo-inositol catabolism in the response to acid stress.

\subsubsection{Urease}

As we indicated above in the section on metabolic pathways, the concentration of urea varied according to the extracellular $\mathrm{pH}$ in the growth medium. Urea metabolism has been reported to be involved in maintaining 


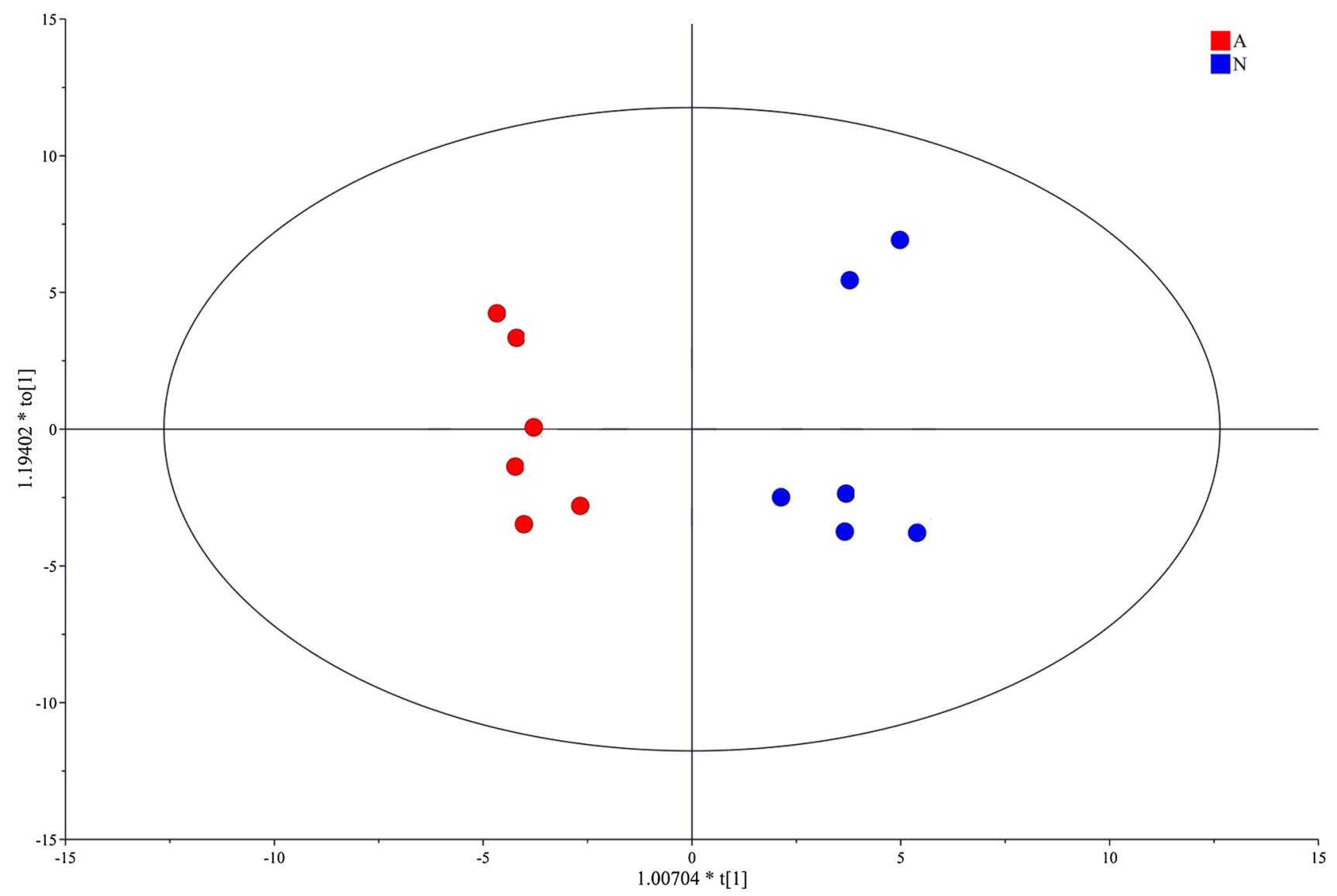

Fig. 1 Analysis of the metabolome fingerprint of $S$. meliloti cultures grown at $\mathrm{pH} 7.0$ and $\mathrm{pH}$ 6.1. S. meliloti cells were grown in minimal medium at $\mathrm{pH} 7.0$ and 6.1, harvested by fast filtration, and frozen. The metabolites were extracted from the thawed cells and analyzed by gas-chromatography-mass-spectrometry. The data from quanti-

intracellular-pH homeostasis in several microorganismse. g., Helicobacter pylori, Streptococcus spp., and Brucella spp. (Mobley et al. 1995; Chen et al. 2000; Bandara et al. 2007). To investigate if a similar role might also be operative in $S$. meliloti, we tested the urease activity in $\operatorname{ATR}(+)$ and ATR(-) rhizobia. Figure 4, panel c accordingly indicates that the urease activity was substantially lower in the $\operatorname{ATR}(+)$ cells compared to activity measured in the cells not adapted to acidity.

\subsection{Quantification of PHB and EPSs in ATR(+) and in ATR(-) rhizobia}

In addition to synthesizing the structural polysaccharides found mainly in the bacterial membranes and cell walls, rhizobia are able to elaborate several secreted polysaccharides, such as the EPSs and cyclic B-glycans, along with polysaccharides that are accumulated internally, such as PHB or glycogen (Zevenhuizen 1981). Because these polymers fulfil diverse functions in free-living cells as well as fication of the identified compounds were used for the multivariate orthogonal partial-least-squares-discriminant analysis. Samples from acid-grown cultures $(A)$ are indicated by red circles and from neutral cultures $(N)$ by blue circles

participating in signalling processes and establishing symbiosis, the biosynthesis or degradation of the EPSs and PHB is highly regulated by environmental conditions (Dilworth et al. 1999; Mendrygal and Gonzalez 2000; Tavernier et al. 1997; Povolo and Casella 2009). In order to determine the influence of acidity on the carbon-storage status of cells that had been grown in batch culture at the two pHs, we quantified the PHB content. The data in Table 2 demonstrate that the amount of $\mathrm{PHB} /$ cell dry weight was significantly lower in the ATR $(+)$ rhizobia at $\mathrm{pH} 6.1$ than in the ATR $(-)$ cells at $\mathrm{pH} 7.0(p \leq 0.01)$. In contrast, the EPS production was significantly higher (Student $t$ test, $p \leq 0.05)$ at $\mathrm{pH} 6.1\left(63.3 \pm 25.1 \mathrm{mg} \mathrm{mg}^{-1}\right.$ dry weight $)$ than at $\mathrm{pH} 7.0\left(15.8 \pm 4.8 \mathrm{mg} \mathrm{mg}^{-1}\right.$ dry weight $)$.

\subsection{Determination of the internal redox state}

The intracellular content of PHB (through a balance of synthesis and degradation) is controlled by the cellular availability of NADH (Uchino et al. 2007). Thus, because of 


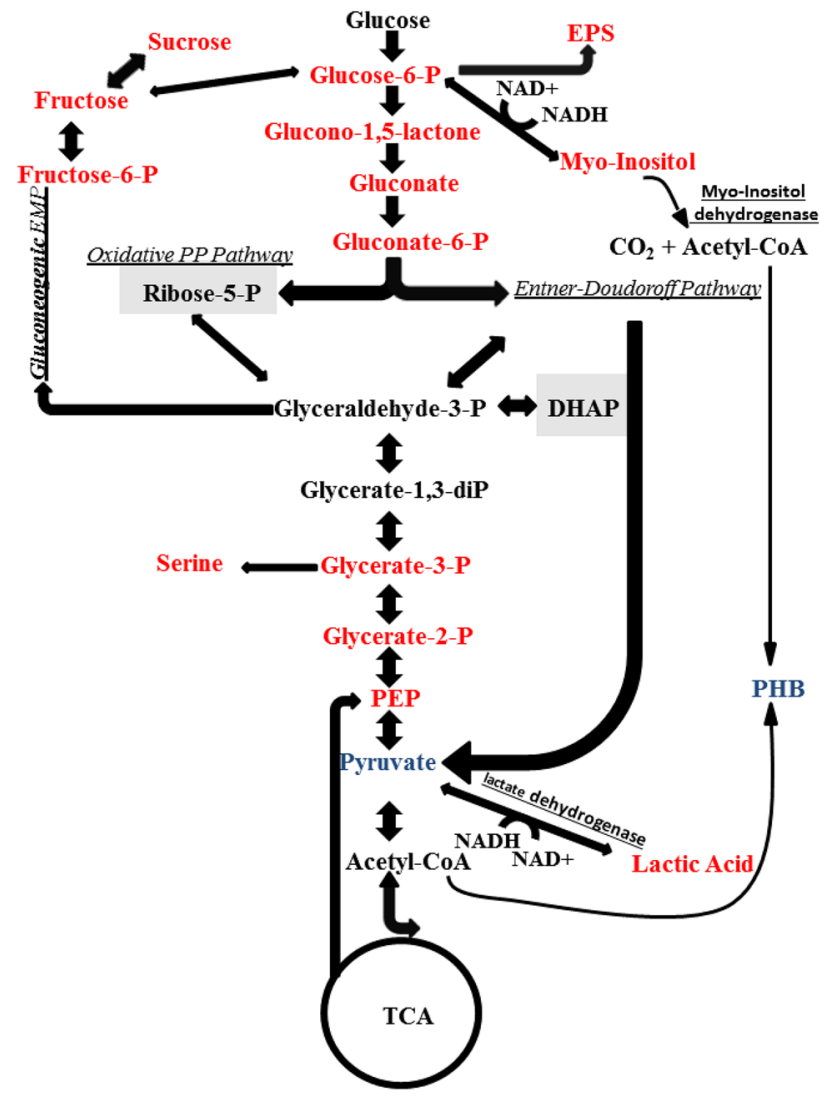

Fig. 2 Metabolism of the carbon source in ATR $(+)$ cells of $S$. meliloti. Schematic representation of the metabolic pathways involving the metabolites with concentrations altered as a result of the external $\mathrm{pH}$. The metabolites shown in red were highly concentrated in acid-grown cells ( $\mathrm{pH} 6.1$ vs. $\mathrm{pH}$ 7.0), whereas the metabolites indicated in dark blue were present at lower concentrations in acidgrown cells. Gray shadowed metabolites in black did not show significant differences when changing the extracellular $\mathrm{pH}$. Unshadowed metabolites in black were not determined. EMP Embden-Meyerhoff pathway, EPS extracellular polysaccharide, DHAP dihydroxyacetone phosphate, $P E P$ phosphoenolpyruvate, $P H B$ polyhydroxybutyrate, $T C A$ tricaboxylic-acid (Krebs) cycle

the intracellular accumulation of PHB cited in the previous section, we decided to characterize the redox state in cells growing at neutral or acid $\mathrm{pH}$ by determining the cytosolic $\mathrm{NADH} / \mathrm{NAD}+$ ratio. That ratio proved to be significantly lower in the ATR $(+)$ cells than in the ATR(-) rhizobia $(p \leq 0.05$; Table 2), hence demonstrating an altered redox state in cells growing at acid $\mathrm{pH}$ as a result of a diminished availability of reduced equivalents of NADH.

\section{Discussion}

The acid-stress response in $S$. meliloti has proven to be a multigenic trait (Draghi et al. 2016), where several molecular changes operate in the acid-challenged rhizobia.
Accordingly, several attempts have been made-mainly through the use of genetic, transcriptomic, or proteomic approaches (Reeve et al. 2004; Tiwari et al. 2004) - to characterize the biochemistry of the rhizobial responses to extracellular acidity. Acidic batch cultures of rhizobia were of particular interest since under this growth condition bacterial cells enter into the so-called $\operatorname{ATR}(+)$ state and display both an increased acid tolerance and an improved competitiveness for nodulation (Draghi et al. 2010). In the present experiments, a metabolomic approach was used to characterize $\operatorname{ATR}(+)$ rhizobia compared to control $\operatorname{ATR}(-)$ cells grown at neutral $\mathrm{pH}$. The results accordingly demonstrated significant changes in several intermediates of the central C metabolism (Table 1). In S. meliloti C sources are catabolized through two main pathways, the Entner-Doudoroff and the pentose-phosphate. The absence of phosphofructokinase in $S$. meliloti enables the use of only the reverse Embden-Meyerhoff (EM) pathway in gluconeogenesis, in this manner providing precursors for polysaccharide biosynthesis (Geddes and Oresnik 2014). The lower half (C3-compounds) of the EM pathway is formally fully operative. The increases in both fructose-6-P and glucose-6-P in the acidic batch cultures are consistent with a recent report on the metabolome of $S$. meliloti grown in a chemostat under acidic conditions where an increased production of EPS was also observed (Hellweg et al. 2009; Geddes et al. 2014).

As was shown in this work (Table 2), the analysis of the $[\mathrm{NADH}] /[\mathrm{NAD}+]$ ratio indicated that the relative amount of the reduced form of this dinucleotide decreased severely under acidity in batch cultures, thus suggesting a higher demand for reducing power in the acid-stressed rhizobia. A limited availability of reducing power is furthermore in agreement with the observed decrease in the PHB content per bacterial cell at low $\mathrm{pH}$. Such a limitation in reducing power might be the origin of the observed increases in different metabolites of the PPP that would be consistent with a higher activity of this pathway at low $\mathrm{pH}$. Increases in several transcripts of the PPP had also been observed in Staphylococcus aureus in acid batch cultures (Bore et al. 2007), thus indicating that the observation presented here might correspond to a more general response to acidity in bacteria. An increase in the oxidative reactions of the PPP (i.e., glucose-6-P $\rightarrow$ glucono-1,5-lactone and then gluconate $\rightarrow$ ribulose-5-P) would be expected to generate a $\mathrm{C}$ overflow which must be eliminated via secondary metabolites like EPS and possibly also through lactate production (Paczia et al. 2012), which intermediate proved to be elevated in the metabolome of the acid-grown rhizobia. The synthesis of lactate in rhizobia has been previously reported as a fermentative response under different stresses such as low temperatures or during the oxygen depletion of batch cultures (Sardesai and Babu 2000; Encarnacion 
Fig. 3 Amino-acid metabolism in ATR(+) cells of $S$. meliloti. Schematic representation of the metabolic pathways involving the metabolites with concentrations altered as a result of the external $\mathrm{pH}$. The metabolites shown in red were highly concentrated in acid-grown cells, whereas the metabolites indicated in dark blue were present at lower concentrations in acid-grown cells. Gray shadowed metabolites in black did not show significant differences when changing the extracellular $\mathrm{pH}$. Unshadowed metabolites in black were not determined. $P P$ pentose-phosphate, DHAP dihydroxyacetone phosphate, PEP phosphoenolpyruvate, TCA tricaboxylic-acid (Krebs) cycle

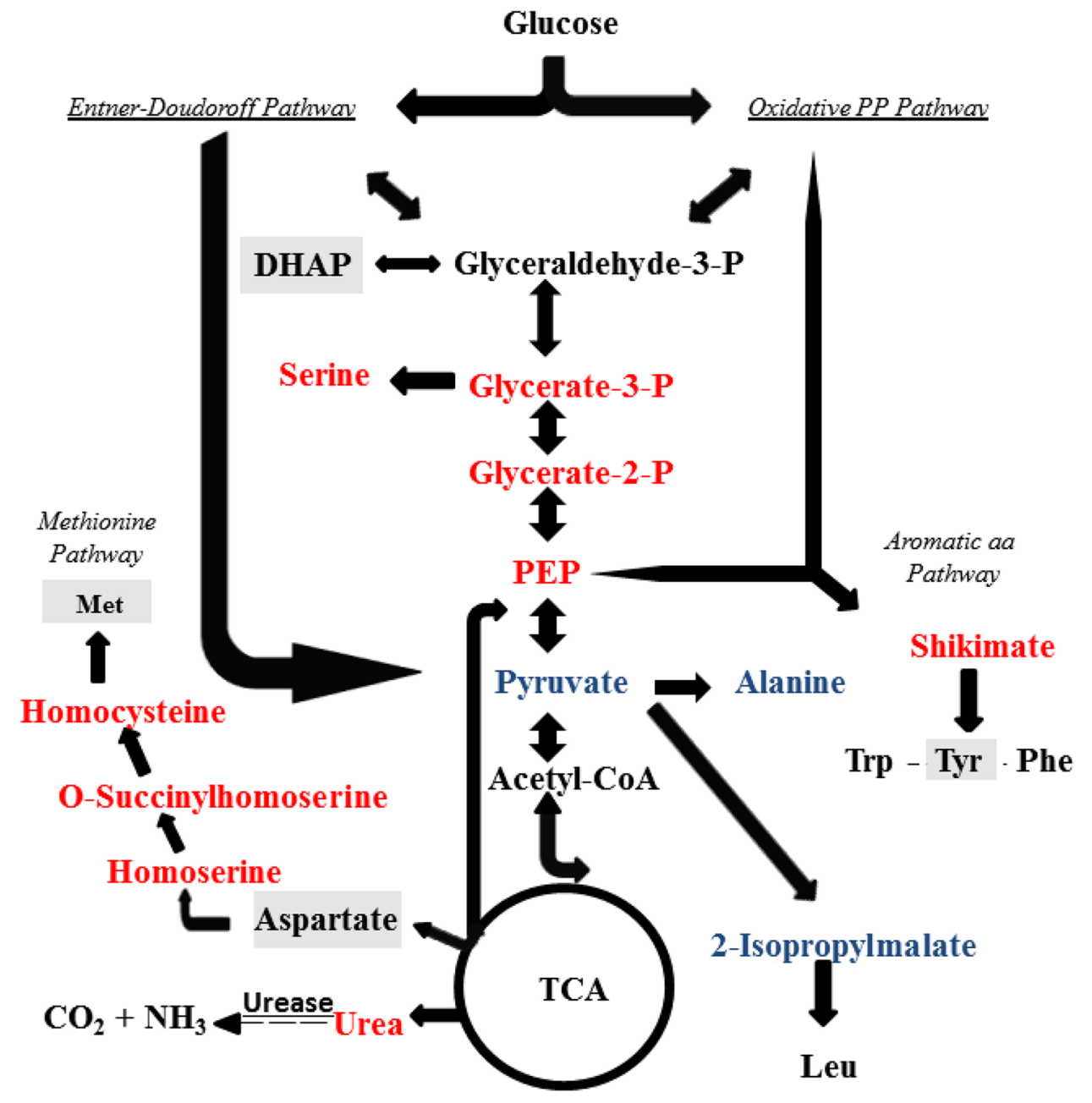

et al. 1995). That several triose-related compounds were increased in the acid-grown rhizobia in batch cultures was remarkable since glycerate-3-P, glycerate-2-P, and phosphoenolpyruvate are upstream intermediates in the biosynthesis of lactate. The intracellular concentrations of several amino acids and related precursors became significantly altered at low $\mathrm{pH}$. The decreased concentration of alanine or 2-isopropylmalate (a precursor in the synthesis of leucine) in acid-grown cells is probably a consequence of the low concentration of pyruvic acid. In contrast, the intracellular concentration of proline increased at low $\mathrm{pH}$, as has also been reported to happen in other bacteria under osmotic stress (da Costa et al. 1998). The concentration of shikimate, an intermediate in the synthesis of aromatic amino acids, was elevated at low $\mathrm{pH}$. Shikimate consumption requires phosphorylation by the shikimate kinase encoded by the aroK gene (Dunn 2015). In Escherichia coli this reaction is rate-limiting in this pathway and the expression of $a r o K$ is under the control of a two-component CpxR/CpxA system that exerts a negative transcriptional control of aroK under stress conditions affecting envelope integrity, such as alkaline stress (Hunke et al. 2012; Vogt and Raivio 2012). Santos et al. (2010) have suggested that the loci SMb20560 and SMb20561 are possible $S$. meliloti homologues to $\mathrm{CpxR} / \mathrm{CpxA}$, respectively. If a regulatory pathway similar to the one observed in E. coli is present and operative in $S$. meliloti, the changes reported by those authors in membrane lipids under acid stress would likely have impacted membrane structure so as to change the concentration of shikimate via a Cpx-like form of aroK regulation (Chen E.et al. 2009). Nevertheless, the means by which the observed increases in intracellular shikimate could promote acid tolerance in rhizobia is not yet clear. Another two-component system that is responsive to acid stress in S. meliloti is the ExoS/ChvI (Hellweg et al. 2009), which loci at low $\mathrm{pH}$ positively regulate several genes of the myo-inositol catabolic pathway including iolB, iolC, iolD, and iolE (Sohlenkamp and Geiger 2016). Under continuous cultivation at $\mathrm{pH} 6.1$ we have also observed an increased transcription of $i d h A$ (Draghi et al. 2016), the gene that encodes a myo-inositol dehydrogenase (Jiang et al. 2001), which activity was found here to be increased 


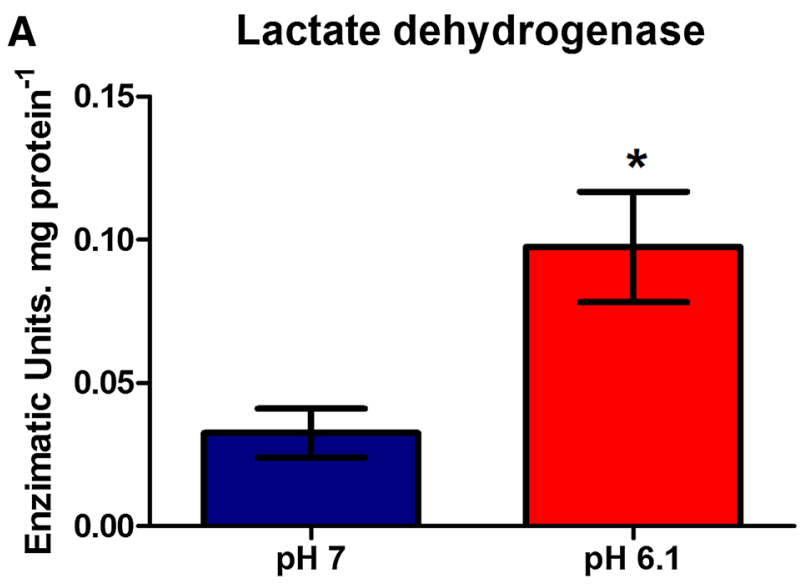

\section{B Myo-Inositol dehydrogenase}
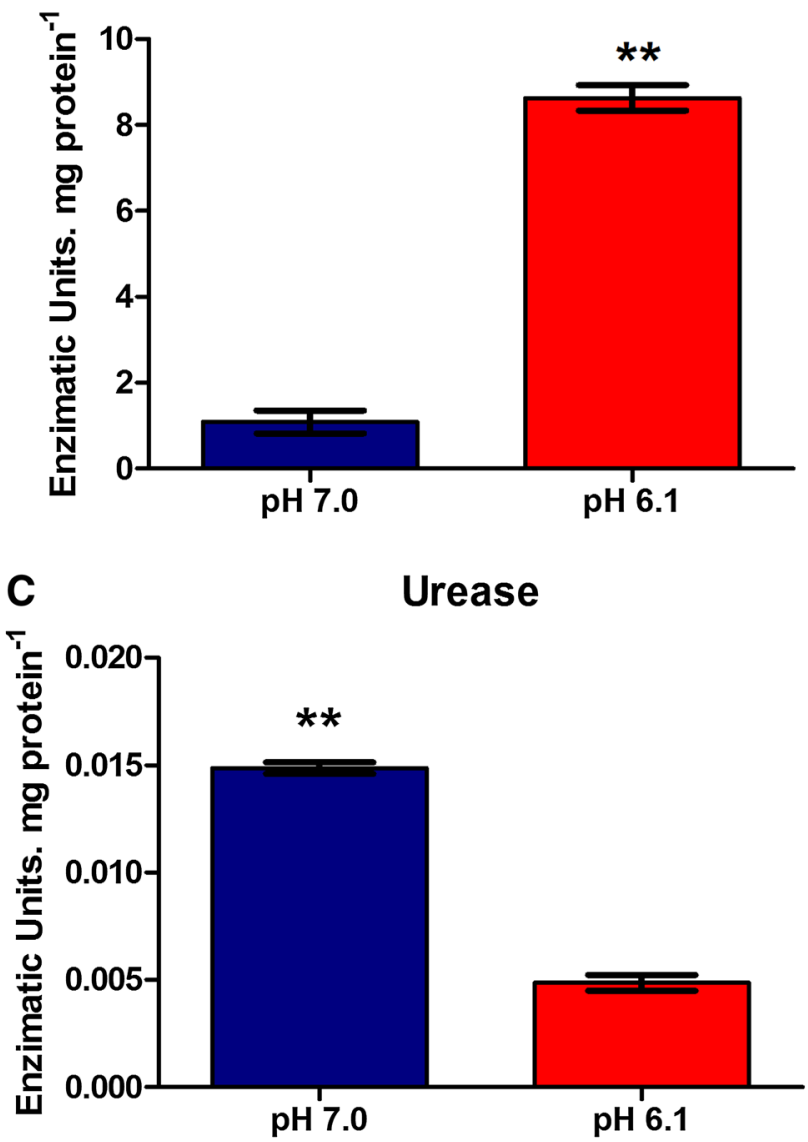

Fig. 4 Enzymatic activities in $\operatorname{ATR}(+)$ and $\operatorname{ATR}(-)$ cells of $S$. meliloti. The figures depict informative enzymatic activities measured in acid-adapted and non-adapted cells along with the corresponding statistical ranges shown in brackets. The statistical differences in the activities were analyzed by the Student $t$ test, indicating comparisons at $p$ values $\leq 0.05(*)$ or $\leq 0.01(* *)$. The data are the mean values from three independent experiments \pm the standard deviations. In the figures, enzymatic activity in units per $\mathrm{mg}$ of protein is plotted on the ordinates for the two growth-medium $\mathrm{pHs}$ indicated on the abscissas by more than eightfold (Fig. 4, Panel b). That in the reaction sequence from glucose to the first intermediate of the myo-inositol degradation pathway a net $\mathrm{NADH}$ is gained might be relevant in view of the decreased intracellular $\mathrm{NADH} / \mathrm{NAD}+$ ratio under acidity.

In order to maintain cytoplasmic-pH homeostasis, bacteria may use different mechanisms addressed at counteracting the effects of increased hydrogen-ion concentrations in the extracellular medium (Lund et al. 2014). In certain microorganisms the hydrolysis of urea to $\mathrm{NH}_{4}+$ and $\mathrm{CO}_{2}$ by urease has been reported to contribute to a sequestering of hydrogen ions from the cytoplasm (Lund et al. 2014). Since ATR $(+)$ rhizobia exhibited a lower urease activity than those grown at neutral $\mathrm{pH}$, the hydrolysis of urea for the purpose of neutralizing intracellular acidity is unlikely to be operative in S. meliloti. The lower urease activity that we observed here (Fig. 4, Panel c) is consistent with the decreased transcription previously reported for the ureC locus encoding the urease alpha-subunit (Draghi et al. 2016). Nonetheless, other urea-independent deamination reactions could contribute to a neutralization of intracellular hydrogen ions by generating ammonium ions. The methionine biosynthetic pathway, for example, generates those ions during the deamination of cystathionine (Ferla and Patrick 2014). In addition, that pathway generates precursors of the membrane-lipid diacylglyceryl- $N, N, N$-trimethylhomoserine, which intermediate has been involved in changes in the composition of the $S$. meliloti membranes under other stress conditions (Geiger et al. 1999). Both the accumulation of the several intermediates of methionine biosynthesis demonstrated in this work and the previously reported increases in their transcripts (Hellweg et al. 2009) support a role for this pathway in facilitating rhizobial growth under conditions of acidity. Further analyses will be required to elucidate the degree of contribution of all these reactions to acid tolerance in S. meliloti.

Acid-stressed S. meliloti manifested several changes in different metabolic pathways while growing in acidic batch cultures. Though the precise relationship between the observed changes and acid tolerance could not always be established, alterations in specific metabolic pathways could be identified in several instances that were related to responses to different abiotic stresses reported in other bacteria. Since ATR $(+)$ rhizobia, whose metabolome we characterized in this work, are also more competitive for nodulation than the non-adapted strains (Draghi et al. 2010), improvements in cultural conditions in accordance with the modifications reported here could serve the practical purpose of obtaining symbiotically more competent inoculants for acidic soils without a loss of viability. 
Table 2 Measurement of intracellular carbon storage and reducingpower balance

\begin{tabular}{llc}
\hline & $\begin{array}{l}\text { PHB content }\left(\mathrm{mg} \mathrm{mg}^{-1} \text { dry }\right. \\
\text { weight })\end{array}$ & NADH/NAD+ratio \\
\hline pH 7.0 & $0.045 \pm 0.0023$ & $12.25 \pm 2.67 *$ \\
pH 6.1 & $0.018 \pm 0.001 * *$ & $2.68 \pm 0.19$ \\
\hline
\end{tabular}

The table shows polyhydroxybutyrate (PHB) content and the balance of intracellular reduced power (NADH/NAD+ratio) in $S$. meliloti cells of the ATR $(+)$ phenotype versus the non-acid-adapted phenotype. The results are the means of triplicate experiments \pm the SDs

*Significant differences at $p$ values $\leq 0.05$

**Significant differences at $p$ values $\leq 0.01$ by the Student $t$ test

Acknowledgements This research was partially supported by the National Science and Technology Research Council (PIP2014/0420, Consejo Nacional de Investigaciones Científicas y Técnicas-CONICET, Argentina) and National Agency for Science and Technology Promotion (PICT 2012/1719). W.O.D., M.F.D.P., F.A., M.J.L., and A.L. are members of CONICET. The authors are grateful to Dr. Donald F. Haggerty for editing the final version of the manuscript.

\section{Compliance with ethical standards}

Conflict of interest None of the authors have any conflict of interest to declare.

Research involving human or animal participants This article does not contain any studies with human or animal subjects.

\section{References}

Bandara, A. B., Contreras, A., Contreras-Rodriguez, A., Martins, A. M., Dobrean, V., Poff-Reichow, S., et al. (2007). Brucella suis urease encoded by ure 1 but not ure 2 is necessary for intestinal infection of BALB/c mice. BMC Microbiology, 7(1), 57.

Barsch, A., Patschkowski, T., \& Niehaus, K. (2004). Comprehensive metabolite profiling of Sinorhizobium meliloti using gas chromatography-mass spectrometry. Functional \& Integrative Genomics, 4(4), 219-230.

Bore, E., Langsrud, S., Langsrud, O., Rode, T. M., \& Holck, A. (2007). Acid-shock responses in Staphylococcus aureus investigated by global gene expression analysis. Microbiology, 153(7), 2289-2303.

Caetano-Anollés, G., Lagares, A., \& Favelukes, G. (1989). Adsorption of Rhizobium meliloti to alfalfa roots: Dependence on divalent cations and $\mathrm{pH}$. Plant and Soil, 117(1), 67-74.

Capela, D., Barloy-Hubler, F., Gouzy, J., Bothe, G., Ampe, F., Batut, J., et al. (2001). Analysis of the chromosome sequence of the legume symbiont Sinorhizobium meliloti strain 1021. Proceedings of the National Academy of Sciences of the United States of America, 98(17), 9877-9882.

Chen, E., Fisher, R., Perovich, V., Sabio, E., \& Long, S. (2009). Identification of direct transcriptional target genes of ExoS/ChvI twocomponent signaling in Sinorhizobium meliloti. Journal of Bacteriology, 191, 6833-6842.

Chen, Y. Y., Weaver, C. A., \& Burne, R. A. (2000). Dual functions of Streptococcus salivarius urease. Journal of Bacteriology, 182(16), 4667-4669. da Costa, M. S., Santos, H., \& Galinski, E. A. (1998). An overview of the role and diversity of compatible solutes in bacteria and Archaea. Advances in Biochemical Engineering/Biotechnology, 61, 117-153.

Dilworth, M. J., Howieson, J. G., Reeve, W. G., Tiwari, R. P., \& Glenn, A. R. (2001). Acid tolerance in legume root nodule bacteria and selecting for it. Australian Journal of Experimental Agriculture, 41, 435-446.

Dilworth, M. J., Rynne, F. G., Castelli, J. M., Vivas-Marfisi, A. I., \& Glenn, A. R. (1999). Survival and exopolysaccharide production in Sinorhizobium meliloti WSM419 are affected by calcium and low pH. Microbiology, 145, 1585-1593.

Draghi, W. O., Del Papa, M. F., Hellweg, C., Watt, S. A., Watt, T. F., Barsch, A., et al. (2016). A consolidated analysis of the physiologic and molecular responses induced under acid stress in the legume-symbiont model-soil bacterium Sinorhizobium meliloti. Scientific Reports, 6, 29278.

Draghi, W. O., Del Papa, M. F., Pistorio, M., Lozano, M., de Los Angeles Giusti, M., Torres Tejerizo, G. A., et al. (2010). Cultural conditions required for the induction of an adaptive acidtolerance response (ATR) in Sinorhizobium meliloti and the question as to whether or not the ATR helps rhizobia improve their symbiosis with alfalfa at low pH. FEMS Microbiology Letters, 302(2), 123-130.

Dunn, M. F. (2015). Key roles of microsymbiont amino acid metabolism in rhizobia-legume interactions. Critical reviews in microbiology, 41(4), 411-451.

Encarnacion, S., Dunn, M., Willms, K., \& Mora, J. (1995). Fermentative and aerobic metabolism in Rhizobium etli. Journal of Bacteriology, 177(11), 3058-3066.

Evans, C. G. T., Herbert, D., \& Tempest, D. W. (1970). The continuous cultivation of micro-organisms. II. Construction of a chemostat. Methods in Microbiology, 2, 277-327.

Ferguson, B. J., Lin, M. H., \& Gresshoff, P. M. (2013). Regulation of legume nodulation by acidic growth conditions. Plant Signaling \& Behavior, 8(3), e23426.

Ferla, M. P., \& Patrick, W. M. (2014). Bacterial methionine biosynthesis. Microbiology, 160, 1571-1584.

Fry, J., Wood, M., \& Poole, P. S. (2001). Investigation of myoinositol catabolism in Rhizobium leguminosarum bv. viciae and its effect on nodulation competitiveness. Molecular PlantMicrobe Interactions 14(8), 1016-1025.

Fuhrer, T., Fischer, E., \& Sauer, U. (2005). Experimental identification and quantification of glucose metabolism in seven bacterial species. Journal of Bacteriology, 187(5), 1581-1590.

Futai, M. (1973). Membrane D-lactate dehydrogenase from Escherichia coli. Purification and properties. Biochemistry, 12(13), $2468-2474$.

Gage, D. J. (2004). Infection and invasion of roots by symbiotic, nitrogen-fixing rhizobia during nodulation of temperate legumes. Microbiology and Molecular Biology Reviews, 68(2), 280-300.

Geddes, B. A., González, J. E., \& Oresnik, I. J. (2014). Exopolysaccharide production in response to medium acidification is correlated with an increase in competition for nodule occupancy. Molecular Plant-Microbe Interactions, 27(12), 1307-1317.

Geddes, B. A., \& Oresnik, I. J. (2014). Physiology, genetics, and biochemistry of carbon metabolism in the alphaproteobacterium Sinorhizobium meliloti. Canadian Journal of Microbiology, 60(8), 491-507.

Geiger, O., Rohrs, V., Weissenmayer, B., Finan, T. M., \& ThomasOates, J. E. (1999). The regulator gene $p h o B$ mediates phosphate stress-controlled synthesis of the membrane lipid diacylglyceryl- $N, N, N$-trimethylhomoserine in Rhizobium (Sinorhizobium) meliloti. Molecular microbiology, 32(1), 63-73. 
Gibson, K. E., Kobayashi, H., \& Walker, G. C. (2008). Molecular determinants of a symbiotic chronic infection. Annual Review of Genetics, 42(1), 413-441.

Glenn, A. R., \& Dilworth, M. J. (1994). The life of root nodule bacteria in the acidic underground. FEMS Microbiology Letters, 123(1-2), 1-9.

Glenn, A. R., Reeve, W. G., Tiwari, R. P., \& Dilworth, M. J. (1999). Acid tolerance in root nodule bacteria. Novartis Foundation Symposium, 221, 112-126.

Graham, S. F., Chevallier, O. P., Kumar, P., Türkoğlu, O., \& BahadoSingh, R. O. (2016). High resolution metabolomic analysis of ASD human brain uncovers novel biomarkers of disease. Metabolomics, 12(4), 62.

Hellweg, C., Puhler, A., \& Weidner, S. (2009). The time course of the transcriptomic response of Sinorhizobium meliloti 1021 following a shift to acidic pH. BMC Microbiology, 9(1), 37.

Hunke, S., Keller, R., \& Muller, V. S. (2012). Signal integration by the Cpx-envelope stress system. FEMS Microbiology Letters, $326(1), 12-22$.

Jiang, G., Krishnan, A. H., Kim, Y. W., Wacek, T. J., \& Krishnan, H. B. (2001). A functional myo-inositol dehydrogenase gene is required for efficient nitrogen fixation and competitiveness of Sinorhizobium fredii USDA191 to nodulate soybean (Glycine max [L.] Merr.). Journal of Bacteriology, 183(8), 2595-2604.

Jones, K. M., Kobayashi, H., Davies, B. W., Taga, M. E., \& Walker, G. C. (2007). How rhizobial symbionts invade plants: the Sinorhizobium-Medicago model. Nature Reviews Microbiology, 5(8), 619-633.

Kistler, W. S., \& Lin, E. C. (1971). Anaerobic L-glycerophosphate dehydrogenase of Escherichia coli: Its genetic locus and its physiological role. Journal of Bacteriology, 108(3), 1224-1234.

Kochian, L. V., Hoekenga, O. A., \& Piñeros, M. A. (2004). How do crop plants tolerate acid soils? Mechanisms of aluminium tolerance and phosphorous efficiency. Annual Review of Plant Biology, 55(1), 459-493.

Kohler, P. R., Zheng, J. Y., Schoffers, E., \& Rossbach, S. (2010). Inositol catabolism, a key pathway in Sinorhizobium meliloti for competitive host nodulation. Applied and Environmental Microbiology, 76(24), 7972-7980.

Law, J. H., \& Slepecky, R. A. (1961). Assay of Poly-beta-hydroxybutyric acid. Journal of Bacteriology, 82(1), 33-36.

Leonardo, M. R., Dailly, Y., \& Clark, D. P. (1996). Role of NAD in regulating the adhE gene of Escherichia coli. Journal of Bacteriology, 178(20), 6013-6018.

Lund, P., Tramonti, A., \& De Biase, D. (2014). Coping with low pH: molecular strategies in neutralophilic bacteria. FEMS Microbiology Reviews, 38(6), 1091-1125.

Mendrygal, K. E., \& Gonzalez, J. E. (2000). Environmental regulation of exopolysaccharide production in Sinorhizobium meliloti. Journal of Bacteriology, 182(3), 599-606.

Mobley, H. L., Island, M. D., \& Hausinger, R. P. (1995). Molecular biology of microbial ureases. Microbiological Reviews, 59(3), $451-480$.

O'Hara, G. W., \& Glenn, A. R. (1994). The adaptive acid tolerance response in root nodule bacteria and Escherichia coli. Archives of Microbiology, 161(4), 286-292.

O’Hara, G. W., Goss, T. J., Dilworth, M. J., \& Glenn, A. R. (1989). Maintenance of intracellular $\mathrm{pH}$ and acid tolerance in Rhizobium meliloti. Applied and Environmental Microbiology, 55(8), 1870-1876.

Paczia, N., Nilgen, A., Lehmann, T., Gätgens, J., Wiechert, W., \& Noack, S. (2012). Extensive exometabolome analysis reveals extended overflow metabolism in various microorganisms. Microbial Cell Factories, 11(1), 122

Poole, P. S., Blyth, A., Reid, C. J., \& Walters, K. (1994). Myo-inositol catabolism and catabolite regulation in Rhizobium leguminosarum bv. viciae. Microbiology, 140(10), 2787-2795.
Povolo, S., \& Casella, S. (2009). Effect of poly-3-hydroxybutyrate synthase mutation on the metabolism of Ensifer (formerly Sinorhizobium) meliloti. Journal of Basic Microbiology, 49(2), 178-186.

Quelas, J. I., Mongiardini, E. J., Pérez-Giménez, J., Parisi, G., \& Lodeiro, A. R. (2013). Analysis of two polyhydroxyalkanoate synthases in Bradyrhizobium japonicum USDA 110. Journal of Bacteriology, 195(14), 3145-3155.

Reeve, W. G., Tiwari, R. P., Guerreiro, N., Stubbs, J., Dilworth, M. J., Glenn, A. R., et al. (2004). Probing for pH-regulated proteins in Sinorhizobium medicae using proteomic analysis. Journal of Molecular Microbiology and Biotechnology, 7(3), 140-147.

Reeve, W. G., Tiwari, R. P., Wong, C. M., Dilworth, M. J., \& Glenn, A. R. (1998). The transcriptional regulator gene phrR in Sinorhizobium meliloti WSM419 is regulated by low pH and other stresses. Microbiology, 144, 3335-3342.

Riccillo, P. M., Muglia, C. I., de Bruijn, F. J., Roe, A. J., Booth, I. R., \& Aguilar, O. M. (2000). Glutathione is involved in environmental stress responses in Rhizobium tropici, including acid tolerance. Journal of Bacteriology, 182(6), 1748-1753.

Santos, M. R., Cosme, A. M., Becker, J. D., Medeiros, J. M., Mata, M. F., \& Moreira, L. M. (2010). Absence of functional TolC protein causes increased stress response gene expression in Sinorhizobium meliloti. BMC Microbiology, 10, 180.

Sardesai, N., \& Babu, C. R. (2000). Cold stress induces switchover of respiratory pathway to lactate glycolysis in psychrotrophic Rhizobium strains. Folia MicroBiologica, 45(2), 177-182.

Sohlenkamp, C., \& Geiger, O. (2016). Bacterial membrane lipids: diversity in structures and pathways. FEMS Microbiology Reviews, 40(1), 133-159.

Solorzano, L. (1969). Determination of ammonia in natural waters by the phenolhypochlorite method. Limnology and Oceanography, 14, 799 .

Tavernier, P., Portais, J., Nava, S., Courtois, J., Courtois, B., \& Barbotin, J. (1997). Exopolysaccharide and Poly-(beta)-Hydroxybutyrate coproduction in two Rhizobium meliloti strains. Applied and Environmental Microbiology, 63(1), 21-26.

Tiwari, R. P., Reeve, W. G., Dilworth, M. J., \& Glenn, A. R. (1996a). Acid tolerance in Rhizobium meliloti strain WSM419 involves a two-component sensor-regulator system. Microbiology, 142, 1693-1704.

Tiwari, R. P., Reeve, W. G., Dilworth, M. J., \& Glenn, A. R. (1996b). An essential role for actA in acid tolerance of Rhizobium meliloti. Microbiology, 142, 601-610.

Tiwari, R. P., Reeve, W. G., Fenner, B. J., Dilworth, M. J., Glenn, A. R., \& Howieson, J. G. (2004). Probing for pH-regulated genes in Sinorhizobium medicae using transcriptional analysis. Journal of molecular Microbiology and Biotechnology, 7(3), 133-139.

Trevelyan, W. E., Forrest, R. S., \& Harrison, J. S. (1952). Determination of yeast carbohydrates with the anthrone reagent. Nature, 170(4328), 626-627.

Uchino, K., Saito, T., Gebauer, B., \& Jendrossek, D. (2007). Isolated poly(3-hydroxybutyrate) (PHB) granules are complex bacterial organelles catalyzing formation of PHB from acetyl coenzyme A (CoA) and degradation of PHB to acetyl-CoA. Journal of Bacteriology, 189(22), 8250-8256.

Vinuesa, P., Neumann-Silkow, F., Pacios-Bras, C., Spaink, H. P., Martinez-Romero, E., \& Werner, D. (2003). Genetic analysis of a pH-regulated operon from Rhizobium tropici CIAT899 involved in acid tolerance and nodulation competitiveness. Molecular Plant-Microbe Interactions, 16(2), 159-168.

Vogt, S. L., \& Raivio, T. L. (2012). Just scratching the surface: an expanding view of the Cpx envelope stress response. FEMS Microbiology Letters, 326(1), 2-11. 
Xia, J., Mandal, R., Sinelnikov, I. V., Broadhurst, D., \& Wishart, D. S. (2012). MetaboAnalyst 2.0: a comprehensive server for metabolomic data analysis. Nucleic Acids Research, 40, W127-133.

Zahran, H. H. (1999). Rhizobium-legume symbiosis and nitrogen fixation under severe conditions and in an arid climate. Microbiology and Molecular Biology Reviews, 63(4), 968-989.
Zevenhuizen, L. P. (1981). Cellular glycogen, beta-1,2,-glucan, poly beta-hydroxybutyric acid and extracellular polysaccharides in fast-growing species of Rhizobium. Antonie van Leeuwenhoek, 47(6), 481-497. 
A metabolomic approach to characterize the acid-tolerance response in Sinorhizobium meliloti.

Draghi, Walter Omar ${ }^{1 *}$; Del Papa, María Florencia ${ }^{1}$; Barsch, Aiko ${ }^{2}$; Albicoro, Francisco $^{1}$; Lozano, M.J. ${ }^{1}$; Pühler, Alfred ${ }^{2}$; Niehaus, Karsten ${ }^{2}$ and Antonio Lagares $^{1}$

${ }^{1}$ IBBM - Instituto de Biotecnología y Biología Molecular. CCT La Plata. CONICET Departamento de Ciencias Biológicas, Facultad de Ciencias Exactas, Universidad Nacional de La Plata- Calles 47 y 115 - (1900) La Plata - Argentina

${ }^{2} \mathrm{CeBiTec}$ - Centrum für Biotechnologie - Universität Bielefeld - Bielefeld - Germany

*Corresponding author

Phone: +54-221-425-0497 ext. 31

Fax: +54-221-422-3409 ext. 56

E-mail:wdraghi@biol.unlp.edu.ar 
Supplementary Figure 1. The permutation plot ( $n=999$ iterations) for the validation of the OPLS-DA model $(\mathrm{R} 2=$ green circles, $\mathrm{Q} 2=$ blue squares $)$. Figure A shows the values plot for Class N (pH 7.0). Figure B shows the values plot for Class A (pH 6.1)

OPLS-DA Validate Model

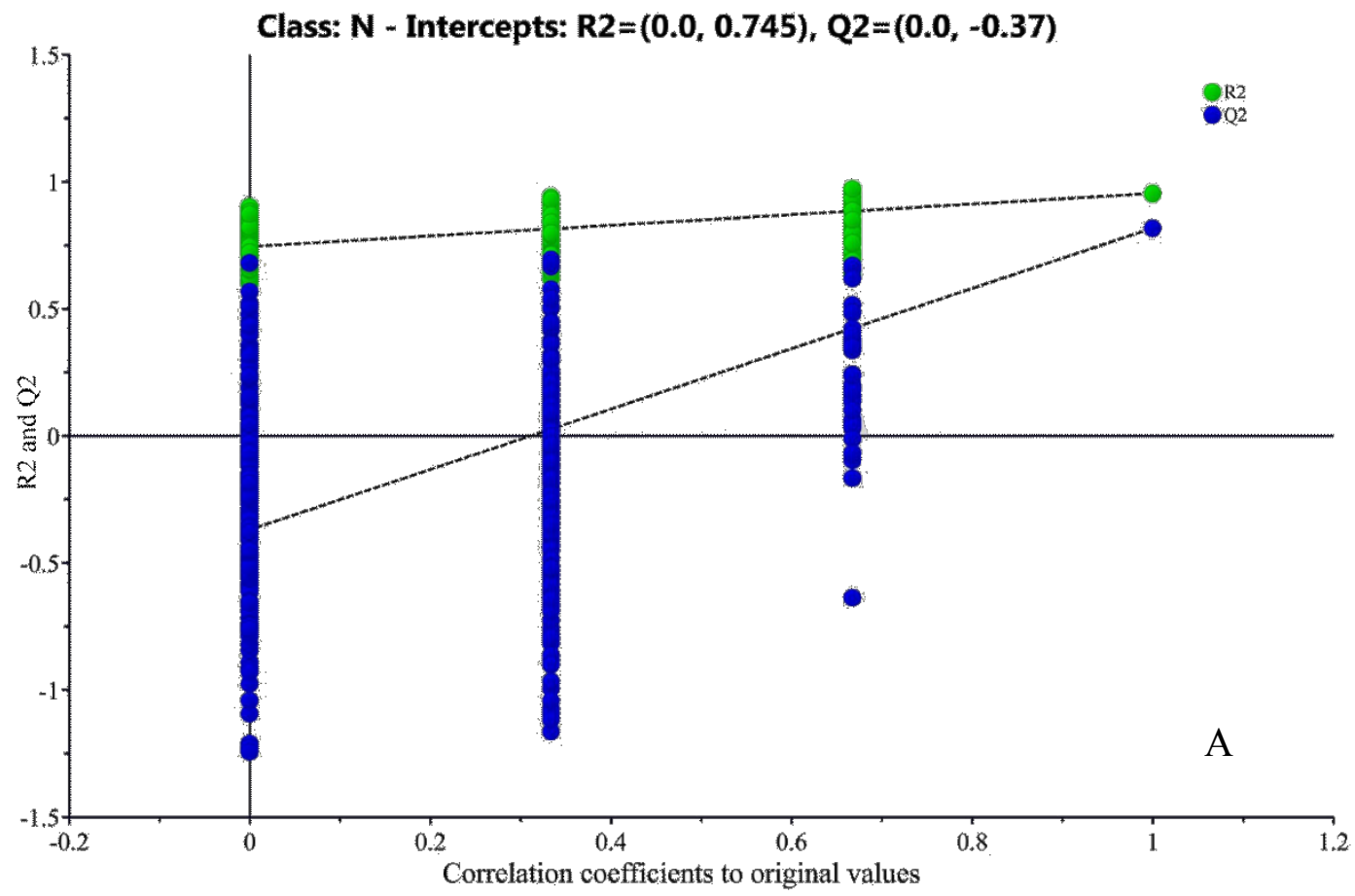

OPLS-DA Validate Model

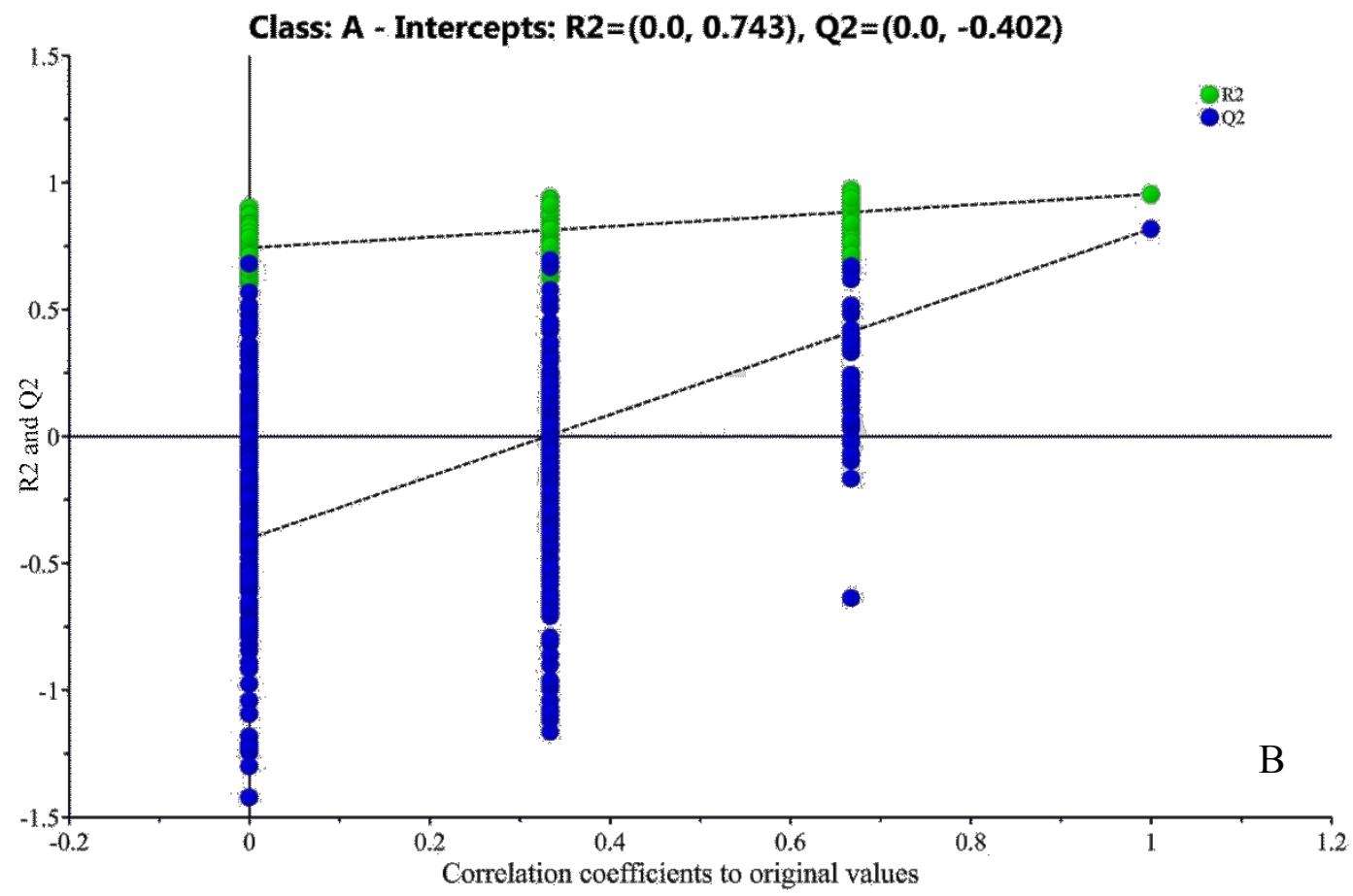


A metabolomic approach to characterize the acid-tolerance response in Sinorhizobium meliloti.

Draghi, Walter Omar $^{1 *}$; Del Papa, María Florencia ${ }^{1}$; Barsch, Aiko ${ }^{2}$; Albicoro, Francisco $^{1}$; Lozano, M.J. ${ }^{1}$; Pühler, Alfred ${ }^{2}$; Niehaus, Karsten ${ }^{2}$ and Antonio Lagares $^{1}$

${ }^{1}$ IBBM - Instituto de Biotecnología y Biología Molecular. CCT La Plata. CONICET Departamento de Ciencias Biológicas, Facultad de Ciencias Exactas, Universidad Nacional de La Plata- Calles 47 y 115 - (1900) La Plata - Argentina

${ }^{2} \mathrm{CeBiTec}$ - Centrum für Biotechnologie - Universität Bielefeld - Bielefeld - Germany

*Corresponding author

Phone: +54-221-425-0497 ext. 31

Fax: +54-221-422-3409 ext. 56

E-mail:wdraghi@biol.unlp.edu.ar 
Supplementary Table 1. Complete list of metabolites detected and quantified by gaschromatography-mass-spectrometry. Table values are the mean and the standard deviation of the quantified metabolites at each $\mathrm{pH}$ condition. Values are expressed as $\mu \mathrm{M}$.

\begin{tabular}{|c|c|c|c|c|c|}
\hline \multicolumn{2}{|c|}{ Amino-acid metabolism } & \multicolumn{2}{|c|}{ pH 7.0} & \multicolumn{2}{|c|}{ pH 6.1} \\
\hline Compound & KEGG ID & Mean & Std. Dev. & Mean & Std. Dev. \\
\hline Alanine & $\mathrm{C} 00041$ & 1.54391 & 0.69036 & 0.774288 & 0.507864 \\
\hline Arginine & C00062 & 0.02715 & 0.005166 & 0.018269 & 0.019114 \\
\hline Asparagine & C00152 & 0.22203 & 0.214452 & 0.199272 & 0.176639 \\
\hline Aspartate & C00049 & 2.98409 & 1.516756 & 2.94633 & 0.969774 \\
\hline B-Alanine & C00099 & 0.04241 & 0.042957 & 0.09243 & 0.164 \\
\hline Glutamate & $\mathrm{C} 00025$ & 25.1339 & 28.78122 & 20.81099 & 26.1459 \\
\hline Glutamine & C00064 & 0.0082 & 0.00957 & 0.02314 & 0.025316 \\
\hline Glycine & C00037 & 2.56421 & 0.914013 & 5.465661 & 5.314584 \\
\hline Isoleucine & C16434 & 0.21796 & 0.095336 & 0.277431 & 0.129578 \\
\hline Leucine & $\mathrm{C} 00123$ & 0.2741 & 0.163127 & 0.266022 & 0.152769 \\
\hline Lysine & C00047 & 2.83557 & 3.25799 & 2.051535 & 3.93744 \\
\hline Methionine & $\mathrm{C} 00073$ & 0.07448 & 0.034714 & 0.103581 & 0.063256 \\
\hline Ornithine & $\mathrm{C} 01602$ & 0.08068 & 0.042987 & 0.256858 & 0.472891 \\
\hline Phenylalanine & C02057 & 0.04781 & 0.048175 & 0.037332 & 0.049408 \\
\hline Proline & C00148 & 0.13059 & 0.085878 & 0.273119 & 0.163547 \\
\hline Shikimate & C00493 & 0.05158 & 0.030165 & 0.070095 & 0.014236 \\
\hline Serine & $\mathrm{C} 00716$ & 0.13411 & 0.099494 & 0.432434 & 0.1603 \\
\hline
\end{tabular}




\begin{tabular}{|c|c|c|c|c|c|}
\hline Threonine & $\mathrm{C} 00188$ & 0.19576 & 0.09834 & 0.21349 & 0.082329 \\
\hline Tyrosine & $\mathrm{C} 00082$ & 4.85171 & 6.132781 & 8.14616 & 11.04532 \\
\hline Valine & C16436 & 1.10921 & 0.947724 & 1.091551 & 0.652902 \\
\hline 2-Isopropylmalate & $\mathrm{C} 02504$ & 0.1398 & 0.047699 & 0.0762 & 0.019358 \\
\hline 2-Aminoadipic acid & C00956 & 0.01115 & 0.007464 & 0.009721 & 0.006428 \\
\hline 4-Aminobutyric acid & $\mathrm{C} 00334$ & 10.2577 & 6.911096 & 8.213695 & 5.451038 \\
\hline Homocysteine & $\mathrm{C} 00155$ & 0.01821 & 0.010421 & 0.028023 & 0.007455 \\
\hline Homoserine & $\mathrm{C} 00263$ & 0.04934 & 0.057668 & 0.685106 & 0.446773 \\
\hline N-Acetylglutamic acid & $\mathrm{C} 00624$ & 37.5061 & 4.044879 & 30.00903 & 10.45601 \\
\hline O-succinyl-homoserine & $\mathrm{C} 01118$ & 0.21006 & 0.050282 & 0.348276 & 0.137951 \\
\hline Pyroglutamate & C01879 & 150.257 & 32.17511 & 118.4096 & 41.33095 \\
\hline S-methyl-cysteine & $\mathrm{C} 03800$ & 0.02269 & 0.018087 & 0.008018 & 0.007234 \\
\hline Urea & $\mathrm{C} 00086$ & 5.43639 & 12.67111 & 1.179374 & 0.571835 \\
\hline
\end{tabular}

\begin{tabular}{l|c|c|c|c|c|}
\hline \multicolumn{2}{|c|}{ Carbohydrate metabolism } & \multicolumn{2}{c|}{$\mathrm{pH} 7.0$} & \multicolumn{2}{c|}{$\mathrm{pH} 6.1$} \\
\hline \multicolumn{1}{|c|}{ Compound } & KEGG ID & Mean & Std. Dev. & Mean & Std. Dev. \\
\hline alpha-Ketoglutarate & C00026 & 1.63041 & 0.757613 & 1.545703 & 0.248305 \\
Citrate & C00158 & 6.1772 & 3.493511 & 3.591422 & 1.244466 \\
Dihydroxyacetone phosphate & C00111 & 0.59156 & 0.145182 & 0.319366 & 0.234114 \\
Fumarate & C00122 & 1.92154 & 0.65651 & 1.789196 & 0.566214 \\
Glycerate-2-P & C00631 & 2.23376 & 1.136395 & 3.866435 & 1.115064 \\
Glycerate-3-P & C00197 & 0.33752 & 0.19751 & 2.084727 & 0.897085 \\
Lactic acid & C00186 & 13.1205 & 7.725381 & 22.5249 & 8.030693
\end{tabular}




\begin{tabular}{|c|c|c|c|c|c|}
\hline Pantothenic acid & $\mathrm{C} 00864$ & 0.36277 & 0.457416 & 0.530468 & 0.555594 \\
\hline Phosphoenolpyruvate & $\mathrm{C} 00074$ & 0.04724 & 0.025015 & 0.101669 & 0.029794 \\
\hline Succinate & $\mathrm{C} 00042$ & 1.29124 & 0.332182 & 1.108992 & 0.25772 \\
\hline alpha-Glycerophosphate & $\mathrm{C} 00093$ & 27.9298 & 8.26881 & 32.89022 & 9.08933 \\
\hline Fructose & $\mathrm{C} 00095$ & 1.30149 & 0.511327 & 2.772275 & 1.338999 \\
\hline Fructose-6-P & $\mathrm{C} 00085$ & 9.76847 & 2.174706 & 12.85586 & 3.934368 \\
\hline Gluconate & $\mathrm{C} 00257$ & 1.34427 & 0.5868 & 3.423506 & 0.743559 \\
\hline Gluconate-6-P & $\mathrm{C} 00345$ & 0.14736 & 0.026713 & 3.542098 & 1.502976 \\
\hline Gluconolactone & $\mathrm{C} 00198$ & 1.03455 & 0.328072 & 1.311721 & 0.359307 \\
\hline Glucose-6-P & $\mathrm{C} 00092$ & 19.5641 & 4.781512 & 23.92453 & 6.237036 \\
\hline Isocitrate & $\mathrm{C} 00311$ & 0.48537 & 0.26172 & 0.315441 & 0.102849 \\
\hline Malate & $\mathrm{C} 00149$ & 5.28929 & 2.12143 & 5.05309 & 1.747398 \\
\hline Oxalic acid & C00209 & 0.21457 & 0.199767 & 0.118928 & 0.034148 \\
\hline Pyruvate & $\mathrm{C} 00022$ & 4.241 & 1.0134 & 2.481093 & 1.140333 \\
\hline Ribose-5-Phosphate & $\mathrm{C} 00117$ & 18.0957 & 3.304717 & 20.63393 & 5.839818 \\
\hline Sucrose & $\mathrm{C} 00089$ & 1.11106 & 0.612954 & 1.882134 & 0.554651 \\
\hline Trehalose & $\mathrm{C} 01083$ & 8.53073 & 20.64843 & 0.084838 & 0.024253 \\
\hline Glycerate & $\mathrm{C} 00258$ & 0.11747 & 0.056362 & 0.195056 & 0.060507 \\
\hline
\end{tabular}

\begin{tabular}{|l|l|l|l|l|r|}
\hline \multicolumn{2}{|c|}{ Fatty-acid metabolism } & \multicolumn{2}{c|}{$\mathrm{pH} 7.0$} & \multicolumn{2}{c|}{$\mathrm{pH} 6.1$} \\
\hline Compound & KEGG ID & Mean & Std. Dev. & Mean & Std. Dev. \\
\hline 2-Hydroxyglutarate & & & & 0.375639 & 0.180518 \\
Maleic acid & C01087 & 0.28278 & 0.095611 & 0.000 & 0 \\
\hline
\end{tabular}


Methylcitrate

\begin{tabular}{|c|c|c|c|c|r|}
\hline \multicolumn{2}{|c|}{ Other metabolic pathways } & \multicolumn{2}{c|}{$\mathrm{pH} 7.0$} & \multicolumn{2}{c|}{$\mathrm{pH} 6.1$} \\
\hline Compound & KEGG ID & Mean & Std. Dev. & Mean & Std. Dev. \\
\hline Myoinositol & & & & 0.612776 & 0.212814 \\
\hline
\end{tabular}

$\begin{array}{llllll}\text { Myoinositol-P } & \text { C01177 } & 0.02671 & 0.025913 & 0.039085 & 0.029138\end{array}$

\begin{tabular}{|c|c|c|c|c|c|}
\hline \multicolumn{2}{|c|}{ Nucleotide Metabolism } & \multicolumn{2}{c|}{$\mathrm{pH} 7.0$} & \multicolumn{2}{c|}{$\mathrm{pH} 6.1$} \\
\hline Compound & KEGG ID & Mean & Std. Dev. & Mean & Std. Dev. \\
\hline Thymine & & & & 0.472676 & 0.099166 \\
Uracil & C00178 & 0.44776 & 0.301848 & & \\
& C00106 & 1.92841 & 0.985978 & 2.524029 & 0.918242
\end{tabular}

